\title{
,anc \\ Mechanically Enhanced Self-Stratified Acrylic/Silicone Antifouling Coatings
}

\author{
Jingjing Xue ${ }^{1}$, Li Wang ${ }^{1}$, Yong Fan ${ }^{1, *}$, Jianing Xu ${ }^{1}$, Jie Zhao ${ }^{2}$, Limei Tian ${ }^{2}$ and Wenbo Du ${ }^{3, *}$ \\ 1 College of Chemistry, Jilin University, Changchun 130022, China; xuejj19@mails.jlu.edu.cn (J.X.); \\ lwang99@jlu.edu.cn (L.W.); xujn@jlu.edu.cn (J.X.) \\ 2 Key Laboratory of Bionic Engineering (Ministry of Education), Jilin University, Changchun 130022, China; \\ jiezhao@jlu.edu.cn (J.Z.); lmtian@jlu.edu.cn (L.T.) \\ 3 National Key Laboratory for Remanufacturing, Army Academy of Armored Forces, Beijing 100072, China \\ * Correspondence: mrfy@jlu.edu.cn (Y.F.); dwbneu@163.com (W.D.)
}

check for updates

Citation: Xue, J.; Wang, L.; Fan, Y.; Xu, J.; Zhao, J.; Tian, L.; Du, W. Mechanically Enhanced Self-Stratified Acrylic/Silicone Antifouling Coatings. Coatings 2022 12, 232. https://doi.org/10.3390/ coatings 12020232

Academic Editor: Esther Rebollar

Received: 28 December 2021

Accepted: 7 February 2022

Published: 11 February 2022

Publisher's Note: MDPI stays neutral with regard to jurisdictional claims in published maps and institutional affiliations.

Copyright: (C) 2022 by the authors. Licensee MDPI, Basel, Switzerland. This article is an open access article distributed under the terms and conditions of the Creative Commons Attribution (CC BY) license (https:// creativecommons.org/licenses/by/ $4.0 /)$

\begin{abstract}
Great attention has been paid to silicone-based fouling-release coatings (FRCs) in the realm of maritime antifouling due to their highly efficient and eco-friendly properties, but many challenges remain for developing a silicone-based FRC that improves its adhesion performance without reducing the antifouling property. Herein, a non-toxic silicone-based FRC has been developed by integrating acrylic resin (AR) with a silicon resin (PDMS) to spontaneously form a self-stratified AR/PDMS coating. The AR/PDMS antifouling coating still has the same fouling-release performance but improved adhesion strength (from 0.4 to $2.0 \mathrm{MPa}$ ) in comparison with pristine PDMS. Moreover, the antifouling coating has proven to be extremely stable in different environments (such as $\mathrm{pH}$, heating, and ultraviolet exposure). The study provides a facile and convenient self-stratified strategy to develop antifouling coatings, contributing to environmentally friendly coatings in marine applications.
\end{abstract}

Keywords: antibiofouling; biofouling resistance; self-stratifying; adhesion force

\section{Introduction}

Marine biofouling can dramatically increase economic and environmental burdens, becoming a worldwide challenge in the realm of the maritime industry [1-5]. According to the America Defense Science and Technology Agency, the estimated total cost associated with hull fouling can reach to $\sim 260$ million per annum in their Navy fleet [6,7]. Marine biofouling is formed by the undesirable accumulation of marine microorganisms, animals, and plants on submerged surfaces causing significant extra fuel consumption and higher emissions of greenhouse gases from marine ships. For marine facilities, biofouling causes and accelerates the corrosion of metal structures, thus greatly increasing maintenance costs [8-10]. Antifouling coatings are the most economic, convenient, and effective approach to preventing the accumulation of marine organisms and metal corrosion. The primary coatings use biocide-containing materials to inhibit their adhesion or kill biofouling organisms [11-13]. Although effective, the use of these paints is increasingly restricted because of their toxicity, which simultaneously affects other non-targeted species [14,15]. Hence, there is a pressing need for developing environmentally friendly and effective antifouling systems.

To date, eco-friendly antifouling strategies, such as fouling-resistant coatings and fouling-release coatings (FRCs), have been developed to combat marine organisms. Foulingresistant coatings can prevent the adhesion of biofouling. They are usually composed of hydrophilic polymers, including those based on zwitterions and poly (ethylene glycol) (PEG) [16]. However, they are generally swollen in ocean conditions, which results in poor mechanical properties and limited applications. Thus, FRCs with highly efficient and eco-friendly properties are particularly attractive in marine antifouling applications [17-19]. Among those, as one of the most common FRCs, poly(dimethylsiloxane) (PDMS) possesses 
both a low elastic modulus and low surface energy, on which the organisms only weakly adhere to the surfaces and can be readily removed from the PDMS surface by gentle mechanical cleaning or the shear forces of water flow, without the involvement of any chemical/biological antifoulants [20-24]. On the other hand, the low elastic modulus and low surface energy also endow the PDMS coating with a low adhesion force to regular substrates. Generally, although the adhesion force between the coating and substrate can be largely enhanced, the introduced coupling agent inevitably increases the coating elasticity modulus and surface energy, hence heavily compromising the surface fouling-release performance $[25,26]$. Therefore, it is still challenging to propose an effective strategy that improves its adhesion performance without reducing the fouling-release property.

Currently, the addition of a bonding layer has been reported to achieve good adhesion ability without reducing the antifouling property [11]. However, this approach is timeconsuming and requires complex procedures and environmental waste generation, which is not always adapted to industrial requirements [27]. As a solution to these short-comings, a new economical and effective self-stratifying system has been developed, allowing a one-step formation of thermodynamically stable multi-layer coating structures after the mixture of two incompatible polymers is applied to a substrate. Accordingly, the system provides not only decreased processing time and economic benefits, but also an optimized surface and good adhesion properties for the coating [28-32]. Moreover, the preferential distribution of concentration through the film thickness greatly eliminates interfacial adhesion failure without compromising the advantages of a multi-layer system [33,34]. In this study, a commercially available acrylic resin (AR) has been considered as the alternative resin in a self-stratified system. ARs serve as reliable anticorrosion materials due to their resistance against adverse environmental conditions and excellent adhesion ability.

Herein, we prepared a novel self-stratified acrylic/PDMS fouling-releasing coating, together with the merits of easy preparation, non-toxicity and a high adhesion on the substrate. Benefiting from its low surface energy, the PDMS segments in the coating tend to be enriched on the outmost layer of the surface, contributing to active fouling-releasing behaviors. Meanwhile, the acrylic components, with relatively high surface energy, readily settle down to the substrate to enhance interfacial adhesion. Moreover, the resultant selfmigration coating can be applied on varied substrates because of its excellent adhesion ability, unique mechanical strengths and facile procedure. Both the adhesive properties of the coating and fouling-release performances were systematically explored.

\section{Materials and Methods}

\subsection{Materials}

Two industrially available resins were selected: an acrylic resin purchased from Guangzhou Huakui Chemical Co., Ltd. (Guangzhou, China) and a silicone resin (184 PDMS elastomer) purchased from Dow Corning Corporation (Shanghai, China). Bacterial strain Paracoccus pantotrophus ATCC 35,512 (P. pantotrophus) was obtained from Chuanxiang Biotechnology, Ltd. (Shanghai, China). Butyl acetate ( $\geq 99.5 \%)$ was purchased from SigmaAldrich (St. Louis, MO, USA) and used as received. Commercially available carbon steel panels ( $Q 235,20 \mathrm{~mm} \times 20 \mathrm{~mm} \times 2 \mathrm{~mm}$ ) and glass panels were used as the substrates. The carbon steel sheets $(\mathrm{C}, 0.2 \%$; $\mathrm{Mn}, 1.2 \%$; and $\mathrm{Si}, 0.35 \%)$ were mechanically polished with emery paper of different grades $(600,900$ and 1200$)$. The glass panels were prepared as squares with the dimensions of $25 \mathrm{~mm} \times 25 \mathrm{~mm} \times 2 \mathrm{~mm}$. The samples were cleaned with acetone and distilled water and dried with nitrogen flow.

\subsection{Stratified Coating Preparation}

Each resin was dissolved evenly in butyl acetate solvent, with an optimized concentration of 50\% ( $w / v$, polymer/solvent). Then, different contents of PDMS solutions (30, 50, and $70 \%$ relative to the acrylic resin weight) were dispersed uniformly into acrylic resin solutions, respectively, and thoroughly stirred by magnetic stirring at $40^{\circ} \mathrm{C}$ for $20 \mathrm{~min}$. The PDMS curing agent (10\%, relative to the PDMS weight) was added to the incompatible 
resin system and mixed for $3 \mathrm{~min}$. The coating suspensions were applied separately on the polished steel substrates and glass substrates by drop-casting. Then, the coating was dried at ambient temperature for $24 \mathrm{~h}$ to avoid an abrupt curing, then cured for $2 \mathrm{~h}$ at $110{ }^{\circ} \mathrm{C}$ in an oven.

\subsection{Adhesion Force Tests}

According to the ISO 4624:2016 standards, the pull-off adhesion tests of the coating on a steel substrate were carried out with the aid of an Instron 1122 tensile tester. The adhesion of the coating was evaluated by the greatest tensile strength that it could bear at the moment of detachment. Additionally, the adhesion of the coatings was further determined according to the ISO-2409:2013 standard cross-cut test. Briefly, cell grids containing 6 parallel and vertical crosscuts were drawn out on a coating surface with a space of $3 \mathrm{~mm}$ between grid blades. Then, $3 \mathrm{M}-600$ adhesive tape $(0.44 \mathrm{~N} / \mathrm{mm})$ was firmly placed on the affected area and followed by quick removal. Finally, the adhesion level was confirmed by the ratio of the remaining coating area to the original coating area, and the larger ratio demonstrated the higher adhesion level.

\subsection{Coating Stability Test}

To further evaluate the stability of the AR-PDMS ${ }_{0.5}$ coating, the coating was immersed in aqueous solutions with different $\mathrm{pH}$ values $(\mathrm{pH}=1,7,10)$. The influence of the thermal aging treatment and UV irradiation on the surface performance of the AR-PDMS ${ }_{0.5}$ coating was also investigated.

\subsection{Mimetic Measurement of Barnacle Adhesion Strength}

The mimetic measurement of barnacle adhesion strength was used to evaluate the adhesion of marine biofouling on the samples. According to ASTM D5618 (2011), an aluminum stud (diameter $10 \mathrm{~mm}$, height $10 \mathrm{~mm}$ ) was stuck on the coatings by epoxy adhesive. The adhesive was cured for $24 \mathrm{~h}$ at $110{ }^{\circ} \mathrm{C}$ in an oven. The maximal shear force was measured by a force gauge (SUNDOO SH-500, Wenzhou Shandu Instrument Co., Ltd., Wenzhou, China).

\subsection{Antibacterial Adhesion Test}

$P$. pantotrophus was employed as the model bacteria. Bacterial cells were grown in the LB culture medium, and then collected by centrifugation and washed with phosphate buffered saline (PBS, $\mathrm{pH}=7.3$ ). Finally, the bacteria were resuspended in PBS to a cell density of $10^{6} \mathrm{CFU} \mathrm{\textrm {mL } ^ { - 1 }}$. The sterilized acrylic/silicone samples $(1 \mathrm{~cm} \times 1 \mathrm{~cm})$ were added by $1 \mathrm{~mL}$ bacterial suspension. After incubation at $37^{\circ} \mathrm{C}$ for $12 \mathrm{~h}$ with a shaker $\left(130 \mathrm{r} \mathrm{min}^{-1}\right)$, the sample surfaces were gently washed by dipping in PBS three times (changed to clean PBS for each step), then placed in fresh medium after 3 min ultrasonic treatment. Moreover, the number of attached cells was determined by a drop plate assay.

\subsection{Other Characterization}

The contact angles (CAs) were measured by a drop shape analysis instrument (DSA, KRÜSSGMBH, Hamburg 100, Shanghai, China). Young's modulus and hardness data were collected with a Nanoindenter (Hysitron Ti-900 Tribolndenter, Hysitron, Shanghai, China). Scanning electron microscopy (SEM, Hitachi SU8020, Hitachi, Guangzhou, China) was used for the detection of the layer interfacial connection and coating thickness. The difference in chemical compositions between the top and bottom coating surface was characterized by cross-section EDS analysis and attenuated total reflectance Fourier-transform infrared spectroscopy (ATR-FTIR, Bruker Vertex 70, Bruker, Shanghai, China). 


\section{Results and Discussion}

\subsection{Characterization of Acrylic/Silicone Coating}

A novel class of dynamic antifouling coating was fabricated on the carbon steel substrate, which was composed of acrylic resin and silicon resin. Figure 1 illustrates the preparation process of the antifouling coating (AR/PDMS) by a two-phase mixture applied on the substrate. The self-stratifying approach allows the one-step formation of thermodynamically stable two-layer structures, combining optimized surface and adhesion properties. The PDMS elastomers are generally prepared by a hydrosilylation reaction (Figure S1). To examine the PDMS migration to the coating surface, their static contact angles were measured (Figure 2a). The probe liquids we used included water, soybean oil and hexadecane with different surface tensions. It is worth noting that the static CAs on the stratified coating surface were very close to the CA values on a pure silicone surface, whatever the probe liquids used, indicating that the PDMS segments with low surface energy migrated to the coating surface. Moreover, the WCA of the AR-PDMS 0.7 surface $\left(\sim 117^{\circ}\right)$ was approximately equal to that of pure PDMS $\left(\sim 118^{\circ}\right)$, showing that $\mathrm{AR}_{-\mathrm{PDMS}} \mathrm{S}_{0.7}$ coatings possessed high hydrophobicity (Figure $2 \mathrm{~b}$ ). It has been reported that hydrophobicity can make the coating stable during long-term seawater immersion [35].

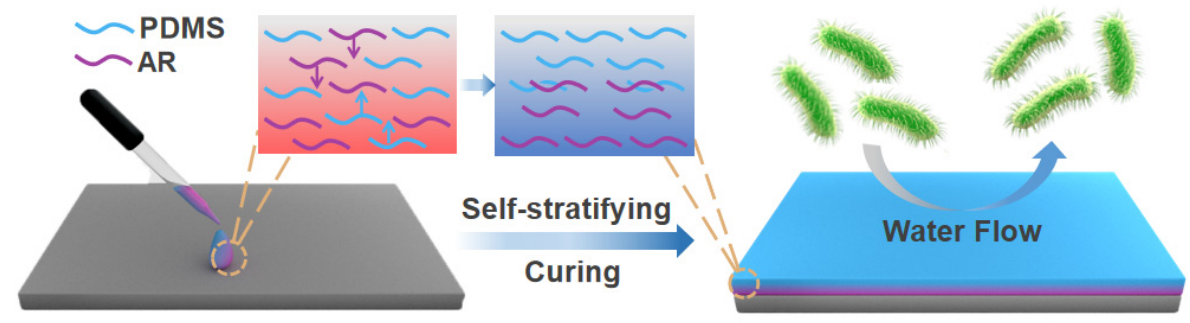

Figure 1. Schematic illustration of the fabrication of antifouling coating.


Figure 2. (a) Contact angles of various probe liquids on various samples (AR, AR-PDMS ${ }_{0.3}, A R-$ PDMS $_{0.5}$, AR-PDMS ${ }_{0.7}$ and PDMS). (b) Photographic images of water droplets on various samples (AR, AR-PDMS ${ }_{0.5}$, AR-PDMS $_{0.7}$ and PDMS). (c) ATR-FTIR spectra of PDMS, AR, top layer and base layer of AR-PDMS ${ }_{0.5}$ (d) Young's modulus and hardness of the samples. 
ATR-FTIR was used to examine the top layer and base layer of the detached AR$\mathrm{PDMS}_{\mathrm{x}}$ coating from the substrate. As for the top layer on both AR-PDMS 0.5 surfaces (Figure 2c), the band at $1010 \mathrm{~cm}^{-1}$ was assigned to the $\mathrm{Si}-\mathrm{O}$ stretch in $\mathrm{Si}-\mathrm{O}-\mathrm{Si}$. The peak at $1258 \mathrm{~cm}^{-1}$ was assigned to symmetric $-\mathrm{CH}_{3}$ deformation within $\equiv \mathrm{Si}-\mathrm{CH}_{3}$ moieties. These characteristic peaks of PDMS confirmed that the coating surface was mainly composed of PDMS components [36]. For the spectrum of the bottom layer, the peak at $1725 \mathrm{~cm}^{-1}$ represented the $\mathrm{C}=\mathrm{O}$ stretch [37], which were characteristic peaks of acrylic resin. It could be concluded that the acrylic resin remains at the bottom of the film during the process.

Since the elasticity plays an important role in the FR performance of the coatings, the elasticity of the coatings was investigated. Figure $2 \mathrm{~d}$ shows the Young's modulus and hardness of the coatings. The pure AR coating showed a high Young's modulus of $\sim 5790 \mathrm{MPa}$ and a very high hardness of $\sim 5788 \mathrm{MPa}$. As for the coating of AR-PDMS ${ }_{0.3}$, a relatively high value of Young's modulus ( 4.7 MPa) was observed. As PDMS content increased, the results showed a declining trend owing to the migration of PDMS to the coating surface and the high flexibility of PDMS. The AR-PDMS 0.5 and AR-PDMS 0.7 possessed relatively low Young's moduli ( 2.6 and $\sim 2.5 \mathrm{MPa}$, respectively), as compared to those of the control PDMS ( 2.1 MPa), indicating that a high elasticity was maintained. A similar trend in coating hardness was also observed. The coating AR-PDMS ${ }_{0.3}$ with the lowest PDMS content showed the highest value in hardness ( 4.4 MPa). The increased PDMS contents caused significant decreases in coating hardness, with values of $\sim 1.8$ and $1.7 \mathrm{MPa}$ for the samples of AR-PDMS 0.5 and $\mathrm{AR}_{\mathrm{PDMS}} \mathrm{PD}_{0.7}$, which are comparable to the PDMS control ( 1.6 MPa).

\subsection{Self-Stratification of Acrylic/Silicone Coating}

As shown in Figure 3a, the typical stratification pattern of AR-PDMS ${ }_{0.5}$ with a thickness of $\sim 230 \mu \mathrm{m}$, was clearly evidenced. Notably, the layers were well-adhered, without any detectable interlayer adhesion failure, indirectly indicating that the stratified coating is mechanically stable and hard to peel between the two layers [33]. To further confirm the composition of the coating (top and bottom layers), the EDS mappings were carried out. The silicon mapping demonstrated that the top layer of the coating was mostly composed of PDMS content, while the carbon mapping indicated that the bottom layer mainly consisted of acrylic resin components (Figure $3 b, c$ ), which is consistent with the results observed in the FTIR spectra. We further used EDS line scanning to examine the axial distribution of silicon and carbon along the acrylic/silicone coating (Figure 3d). Notably, the line scan analysis revealed that the gradual increase in silicon content was accompanied by a decrease in carbon content at the interface of the two-layer system (scanning distance: $38-45 \mu \mathrm{m})$. The formation of gradient structures may be due to the faster curing rate of the coating than the phase separation rate, resulting in the coating curing before complete separation [28]. This result is critical for us to explain the reason why the coating possessed the mechanically enhanced performance as listed in the following section. 

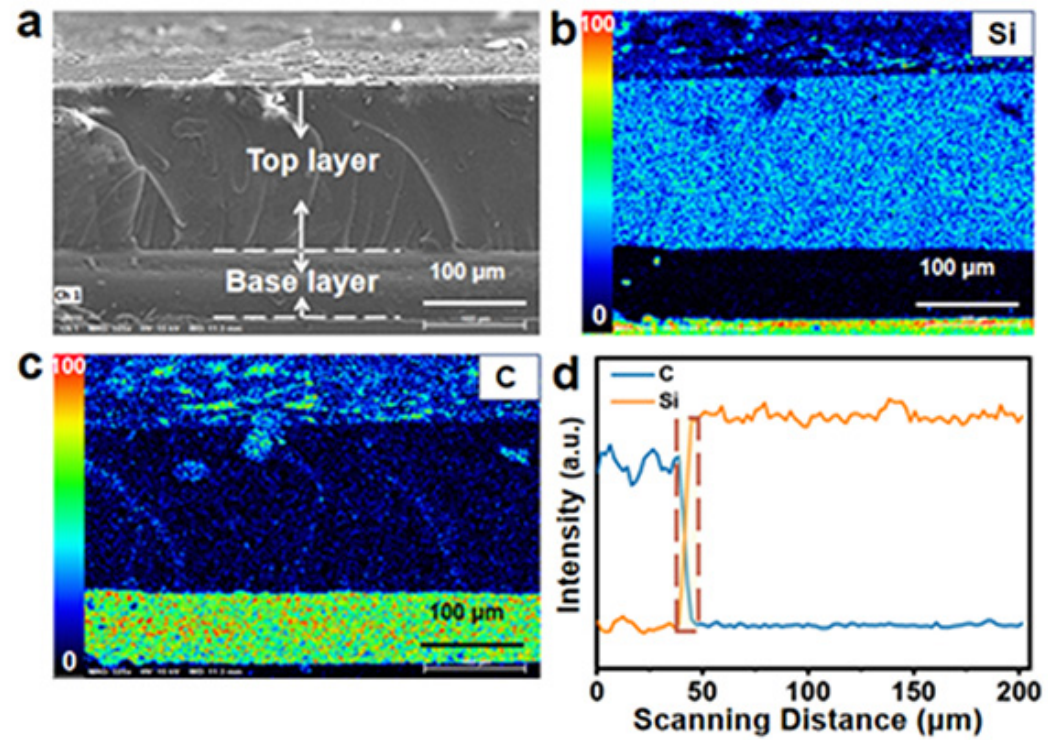

Figure 3. (a) SEM micrograph; EDS elemental mappings; (b) silicon element; and (c) carbon element on a cross-section of AR-PDMS 0.5 coating. (d) Linear element distributions in the cross-section parallel of AR-PDMS 0.5 coating.

\subsection{Coating Adhesion of AR-PDMS ${ }_{x}$ Coatings}

Robust adhesion is a significant precondition for coating applications. Here, a pull-off test was adopted to investigate the adhesion behaviors of between the AR-PDMS $x$ coating and the corresponding metal substrates. As shown in Figure 4a, the PDMS control exhibited a weak adhesion strength $(\sim 0.4 \mathrm{MPa})$ due to its nonpolar chemical nature, making it easy to detach from the metal substrate. In sharp contrast, as the presence of the acrylic component increased, the adhesion strength of AR-PDMS $x$ coatings showed much higher adhesion strength, caused by the migration of acrylic resin to the substrate. Although the pull-off strength of AR-PDMS $S_{x}$ declined to a slight degree compared to the pure acrylic coating, the adhesion force still showed a much higher value to $\sim 2.00 \mathrm{MPa}$, as compared to the PDMS control. To explore whether the stratified coating can be peeled off between the top and bottom layers, an analysis of the interfacial adhesion properties was conducted. The AR-PDMS $x$ exhibited a higher interfacial adhesion strength than traditional coatings with a two-step painting process (Figure $4 \mathrm{~b}$ ). The two-layer coating showed an adhesion strength of $\sim 0.6 \mathrm{MPa}$. In contrast, the AR-PDMS ${ }_{0.7}$ and AR-PDMS ${ }_{0.5}$ coatings showed greater interfacial adhesion strength: $1.5 \mathrm{MPa}$ and $1.2 \mathrm{MPa}$, respectively. This is probably because curing agents may enhance the compatibility of two resin combinations and could provide efficient bonding between layers [28]. We further evaluated AR-PDMS 0.5 coating adhesion by a cross-cut tape test. The photographs shown in Figure S2 demonstrated that AR-PDMS 0.5 exhibited a superior adhesion to metal substrates after the scratch and tape-peeling process, compared to pure PDMS coating. The edges of the sample cuts were intact without any coating detachment, demonstrating that AR-PDMS ${ }_{0.5}$ was classified to grade 0 (excellent adhesion strength). Moreover, the excellent adhesion performance made the coating stable during long-term artificial seawater immersion (Figure S3). Additionally, we examined the adhesion performance of AR-PDMS ${ }_{x}$ coatings to the glass base, which also showed an outstanding adhesive force (Figure S4). 



Figure 4. (a) The adhesion strength of AR-PDMS ${ }_{x}$ coatings to the steel substrate. (b) The interfacial adhesion strength of AR-PDMS $x$ coatings. Variation of WCAs on the AR-PDMS 0.5 coating: (c) immersed in $\mathrm{pH}=4,7$, 10 solutions for 15 days; (d) exposed to a triple-purpose UV lamp $\left(365 \mathrm{~nm}, 5 \mathrm{~mW} / \mathrm{cm}^{2}\right)$ for 15 days; (e) upon heat treatment at $100{ }^{\circ} \mathrm{C}$ for 15 days; (f) as a function of abrasion cycles.

\subsection{Coating Stability and Abrasion Resistance}

The marine environments vary greatly in different areas regarding temperature, $\mathrm{pH}$, and other factors. Therefore, the influences of the acid-base immersion, UV irradiation and thermal aging treatment on the surface properties of the AR-PDMS 0.5 coating were investigated. The AR-PDMS ${ }_{0.5}$ was immersed in an acid $(\mathrm{pH}=4)$, alkali $(\mathrm{pH}=10)$ and aqueous solution, respectively, for different incubation times ranging from 0 to 15 days. Figure $4 \mathrm{c}$ shows that the WCAs had virtually no change on the surface after being immersed in three solutions for 15 days, indicating that the coating possessed excellent $\mathrm{pH}$ stability. Moreover, Figure $4 \mathrm{~d}$ shows the results of UV aging resistance, obtained by exposing the $\mathrm{AR}_{-P D M S} \mathrm{P}_{0.5}$ to a UV lamp $\left(365 \mathrm{~nm}, 5 \mathrm{~mW} / \mathrm{cm}^{2}\right)$. Upon UV exposure for 15 days, WCAs remained constant at $2.1^{\circ} \pm 0.2^{\circ}$. Subsequently, the thermal aging test was performed by heat treatment at $100{ }^{\circ} \mathrm{C}$ for 15 days (Figure 4e). Within this interval, the CAs remained nearly constant over time, demonstrating a superior high-temperature resistance. These results indicated that the AR-PDMS 0.5 coating possessed a reliable durability, which could bear such harsh conditions such as different $\mathrm{pH}$ values, UV irradiation and heating treatment.

Mechanical robustness is also a key property of coatings in practical applications; therefore, a rigorous method was used to further study the mechanical stability of the AR-PDMS ${ }_{0.5}$ coating. The AR-PDMS ${ }_{0.5}$ coatings were placed on a 2000-mesh sandpaper, then a $50 \mathrm{~g}$ weight was set up above the sample. Each cycle included a rightward thrust motion, followed by a leftward thrust motion of the coating on 2000-mesh sandpaper, with a wear distance of $10 \mathrm{~cm}$. Figure $4 \mathrm{f}$ shows that the WACs on the AR-PDMS 0.5 surface exhibited minimal change with the increasing number of cycles of sandpaper abrasion. After 100 cycles of sand abrasion, the CA of the coating slightly decreased from $115.4^{\circ} \pm 2.9^{\circ}$ to $112.4^{\circ} \pm 1.8^{\circ}$. Clearly, the antifouling coating of AR-PDMS ${ }_{0.5}$ was nicely preserved against sandpaper abrasion. 


\subsection{Antifouling Property}

To evaluate the antifouling ability of the AR-PDMS ${ }_{0.5}$ coating, the anti-smudge performance of the AR-PDMS 0.5 against ink was investigated. In Figure 5a, the ink formed distinct marks on the AR coating, and the ink stain was not removed by wiping with a cotton ball. By contrast, the ink on the PDMS and AR-PDMS 0.5 surfaces contracted into weak patchy marks. Moreover, the ink trace was readily wiped off with a cotton ball. These results showed that the AR-PDMS ${ }_{0.5}$ coating had a good antifouling performance when soaked in ink.
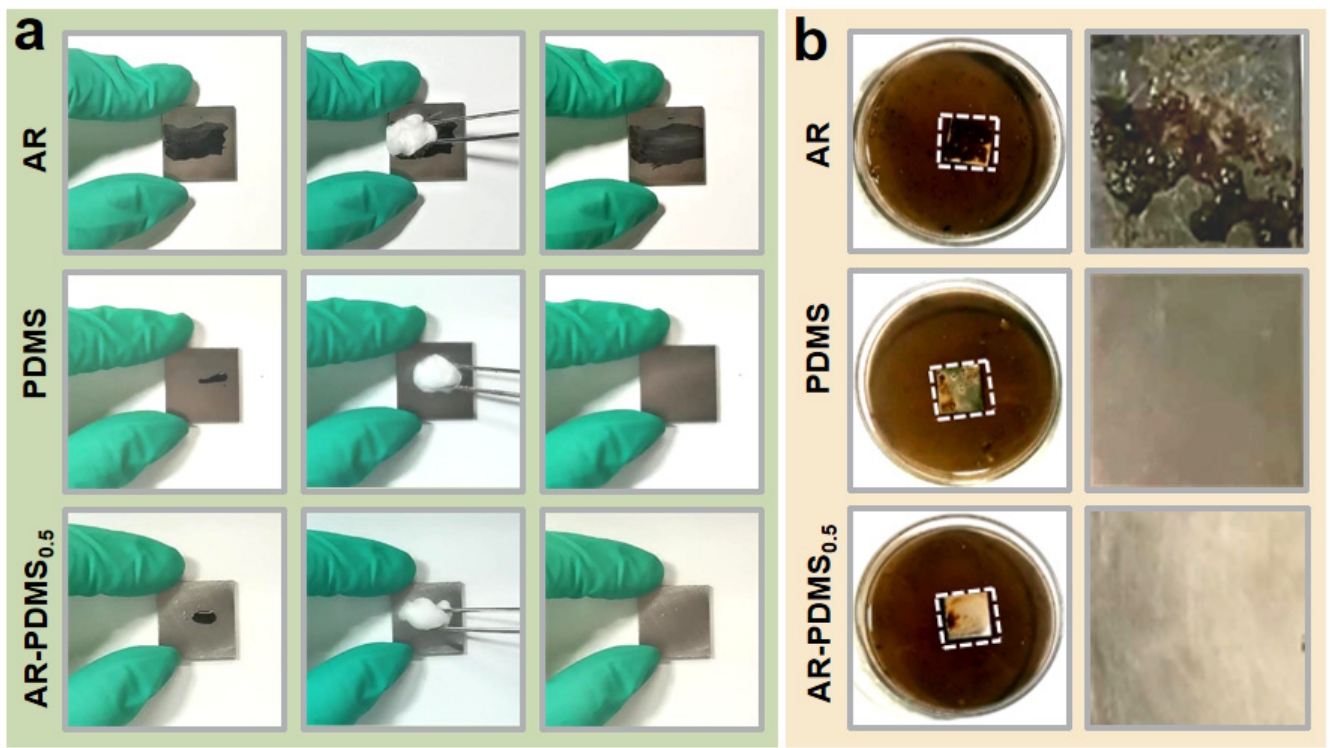

Figure 5. Photographs of a series of antifouling tests (a) an oil-based permanent ink marker on the sample coatings. (b) exposing in an aqueous suspension of sludge for $12 \mathrm{~h}$.

Moreover, the submerged surface of the hull will inevitably contact and adhere to the sludge in the seawater. Thus, the coatings were tested for their ability to resist sludge adhesion by natural sludge suspension. As shown in Figure 5b, after $12 \mathrm{~h}$ of exposure to natural sludge suspension, compared to pristine AR coatings, there was basically no sludge adhesion on the AR-PDMS 0.5 surface, exhibiting excellent anti-sludge adhesion properties. We also applied the AR-PDMSx coating on glass substrates (Figure S5). The excellent anti-smudge property of the coating toward the glass substrate was attributed to the migration of PDMS to the coating surface.

\subsection{Antibacterial Adhesion Performance}

Previous reports have shown that bacterial adhesion is a pivotal step in biofilm formation [38]. Therefore, P. pantotrophus was used as the representative bacteria to test the antibacterial adhesion of AR-PDMS $x$ coatings. As shown in Figure 6a,b, after $12 \mathrm{~h}$ exposure in bacterial suspension, high-density P. pantotrophus bacterial colonies $\left(2.5 \times 10^{5} \mathrm{cfu} / \mathrm{cm}^{2}\right)$ on the AR coating were observed. In comparison, very few P. pantotrophus bacterial colonies could be found on the PDMS $\left(5.2 \times 10^{4} \mathrm{cfu} / \mathrm{cm}^{2}\right)$, PDMS-AR $0.5\left(5.3 \times 10^{4} \mathrm{cfu} / \mathrm{cm}^{2}\right)$, and PDMS-AR $0.7\left(5.4 \times 10^{4} \mathrm{cfu} / \mathrm{cm}^{2}\right)$ coatings, indicating that those coatings exhibited $\sim 80 \%$ reduction in bacterial adhesion. 




Figure 6. Antibacterial adhesion tests. (a) Colonial morphology images after $12 \mathrm{~h}$ exposure, (b) numbers of P. pantotrophus after $12 \mathrm{~h}$ exposure attached on the AR, PDMS, AR-PDMS ${ }_{0.5}$, and AR-PDMS 0.7 coating surfaces. (c) Removal strength in the pseudo barnacle adhesion test.

\subsection{Mimetic Measurement of Barnacle Removal Strength}

The mimetic pseudo barnacle adhesion is widely used to evaluate the barnacle adhesion strength in the lab [35]. As shown in Figure 6c, the removal strength (RS) of AR-PDMS $x$ coating surfaces was significantly decreased (nearly $\sim 84 \%$ reduction) compared to that of control AR ( 1.80 MPa). Both AR-PDMS ${ }_{0.5}$ and AR-PDMS 0.7 displayed a largely decreased removal strength, ranging from $\sim 0.29$ to $\sim 0.28 \mathrm{MPa}$, which was almost comparable to that of the PDMS control $(\sim 0.25 \mathrm{MPa})$. It could be expected that the attached barnacles on the AR-PDMS $x$ should be easily removed by the hydrodynamic forces at a low ship speed in a marine environment. Considering the performances of both mechanical stability and adhesion strength together, the AR-PDMS 0.5 was considered as the optimized candidate for potential antifouling applications.

\section{Conclusions}

In summary, a novel AR/PDMS self-stratified coating was developed for the first time with the merits of easy preparation and non-toxicity. This self-stratifying effect was conducive to the low surface energy characteristics of the coating surface and the formation of good adhesion to the substrate. The coating exhibited remarkable anti-smudge properties as well as antibiofouling performance, owing to the surface migration of the low surface energy PDMS elastic segments. The resultant coating showed a remarkably improved adhesion strength to the substrate (2.0 MPa), as compared to a pure PDMS coating (0.4 MPa). Moreover, this coating also demonstrated a robust stability, which can ensure normal functioning under extreme conditions such as acid/alkali solutions, heating and UV exposure. Overall, a self-stratified AR/PDMS fouling-releasing coating might provide a new method that can effectively overcome the challenges of biofouling in the field of maritime applications.

Supplementary Materials: The following supporting information can be downloaded at: https: / / www.mdpi.com/article/10.3390/coatings12020232/s1, Figure S1: Hydrosilylation reaction for the preparation of silicone elastomers, Figure S2: Cross-cut tape test results of (a) PDMS and (b) AR-PDMS ${ }_{0.5}$, Figure S3: Photographic images of AR-PDMS ${ }_{0.5}$ coatings after immersion in ASW for 0,10 , and $30 \mathrm{~d}$, Figure S4: The adhesion strength of AR-PDMS ${ }_{\mathrm{x}}$ coatings to the glass substrate, 
Figure S5: Photographs of a series of antifouling tests (a) an oil-based permanent ink marker on the sample coatings. (b) exposing in an aqueous suspension of sludge for $12 \mathrm{~h}$.

Author Contributions: Literature search, J.X. (Jingjing Xue), L.W., Y.F., J.X. (Jianing Xu), and J.Z.; Study design, J.X. (Jingjing Xue), J.Z., L.T. and W.D.; Data collection, J.X. (Jingjing Xue), L.T., Y.F. and W.D.; Data analysis, Y.F., J.X. (Jianing Xu), J.Z., L.W.; Data interpretation, J.X. (Jingjing Xue), Y.F., J.Z. and W.D.; Resources, J.Z., L.W., J.X. (Jianing Xu) and L.T.; Validation, Y.F., J.Z. and W.D.; Writing-original draft, J.X. (Jingjing Xue), L.W., J.X. (Jianing Xu) and L.T.; Writing-review and editing, J.Z., Y.F. and W.D. All authors have read and agreed to the published version of the manuscript.

Funding: This work was supported by the Science and Technology Development Plan Project of Jilin Province (Nos. 20190201155JC and 20190201278JC), the Young and Middle-aged Technology Innovation Leading Talents and Team Projects of Science and Technology Development Plan of Jilin Province (20200301013RQ), the Natural Science Foundation of Guangxi Province (No. 2020GXNSFAA238041), the Preresearch Foundation of Equipment Key Laboratory (Grant No. JCKY 61420052005), and the Interdisciplinary Integration and Innovation Project of Jilin University for Young Scholar.

Institutional Review Board Statement: Not applicable.

Informed Consent Statement: Not applicable.

Data Availability Statement: The data that support the findings of this study are available from the corresponding author, upon reasonable request.

Conflicts of Interest: The authors declare that they have no known competing financial interests or personal relationships that could have appeared to influence the work reported in this paper.

\section{References}

1. Banerjee, I.; Pangule, R.C.; Kane, R.S. Antifouling coatings: Recent developments in the design of surfaces that prevent fouling by proteins, bacteria, and marine organisms. Adv. Mater. 2011, 23, 690-718. [CrossRef] [PubMed]

2. Callow, J.A.; Callow, M.E. Trends in the development of environmentally friendly fouling-resistant marine coatings. Nat. Commun. 2011, 2, 244. [CrossRef] [PubMed]

3. Chen, X.; Suwarno, S.R.; Chong, T.H.; McDougald, D.; Kjelleberg, S.; Cohen, Y.; Fane, A.G.; Rice, S.A. Dynamics of biofilm formation under different nutrient levels and the effect on biofouling of a reverse osmosis membrane system. Biofouling 2013, 29, 319-330. [CrossRef] [PubMed]

4. Selim, M.S.; Shenashen, M.A.; El-Safty, S.A.; Higazy, S.A.; Selim, M.M.; Isago, H.; Elmarakbi, A. Recent progress in marine foul-release polymeric nanocomposite coatings. Prog. Mater. Sci. 2017, 87, 1-32. [CrossRef]

5. Yebra, D.M.; Kiil, S.; Dam-Johansen, K. Antifouling technology-past, present and future steps towards efficient and environmentally friendly antifouling coatings. Prog. Org. Coat. 2004, 50, 75-104. [CrossRef]

6. Patterson, A.L.; Wenning, B.; Rizis, G.; Calabrese, D.R.; Finlay, J.A.; Franco, S.C. role of backbone chemistry and monomer sequence in amphiphilic oligopeptide- and oligopeptoid-functionalized PDMS- and PEO-based block copolymers for marine antifouling and fouling release coatings. Macromolecules 2017, 50, 2656-2667. [CrossRef]

7. Schultz, M.P.; Bendick, J.A.; Holm, E.R.; Hertel, W.M. Economic impact of biofouling on a naval surface ship. Biofouling 2011, 27, 87-98. [CrossRef]

8. Genzer, J.; Efimenko, K. Recent developments in superhydrophobic surfaces and their relevance to marine fouling: A review. Biofouling 2006, 22, 339-360. [CrossRef]

9. Krishnan, S.; Weinman, C.J.; Ober, C.K. Advances in polymers for anti-biofouling surfaces. J. Mater. Chem. 2008, 18, 3405-3413. [CrossRef]

10. Xie, Q.; Pan, J.; Ma, C.; Zhang, G. Dynamic surface antifouling: Mechanism and systems. Soft Matter 2019, 15, 1087-1107. [CrossRef]

11. Chernousova, S.; Epple, M. Silver as antibacterial agent: Ion, nanoparticle, and metal. Angew. Chem. Int. Ed. Engl. 2013, 52, 1636-1653. [CrossRef] [PubMed]

12. Hu, P.; Xie, Q.; Ma, C.; Zhang, G. Silicone-Based fouling-release coatings for marine antifouling. Langmuir 2020, 36, 2170-2183. [CrossRef] [PubMed]

13. Ytreberg, E.; Karlsson, J.; Eklund, B. Comparison of toxicity and release rates of Cu and Zn from anti-fouling paints leached in natural and artificial brackish seawater. Sci. Total Environ. 2010, 408, 2459-2466. [CrossRef]

14. Amara, I.; Miled, W.; Slama, R.B.; Ladhari, N. Antifouling processes and toxicity effects of antifouling paints on marine environment. A review. Environ. Toxicol. Pharmacol. 2018, 57, 115-130. [CrossRef] [PubMed]

15. Champ, M.A. Economic and environmental impacts on ports and harbors from the convention to ban harmful marine anti-fouling systems. Mar. Pollut. Bull. 2003, 46, 935-940. [CrossRef] 
16. Baier, R.E. Surface behaviour of biomaterials: The theta surface for biocompatibility. J. Mater. Sci. Mater. Med. 2006, 17, 1057-1062. [CrossRef]

17. Lejars, M.; Margaillan, A.; Bressy, C. Fouling release coatings: A nontoxic alternative to biocidal antifouling coatings. Chem. Rev. 2012, 112, 4347-4390. [CrossRef]

18. Lu, Z.; Chen, Z.; Guo, Y.; Ju, Y.; Liu, Y.; Feng, R.; Xiong, C.; Ober, C.K.; Dong, L. Flexible hydrophobic antifouling coating with oriented nanotopography and nonleaking capsaicin. ACS Appl. Mater. Interfaces 2018, 10, 9718-9726. [CrossRef]

19. Yasani, B.R.; Martinelli, E.; Galli, G.; Glisenti, A.; Mieszkin, S.; Callow, M.E.; Callow, J.A. A comparison between different fouling-release elastomer coatings containing surface-active polymers. Biofouling 2014, 30, 387-399. [CrossRef]

20. Guo, H.; Yang, J.; Zhao, W.; Xu, T.; Lin, C.; Zhang, J.; Zhang, L. Direct formation of amphiphilic crosslinked networks based on PVP as a marine anti-biofouling coating. Chem. Eng. J. 2019, 374, 1353-1363. [CrossRef]

21. Kim, J.; Nyren-Erickson, E.; Stafslien, S.; Daniels, J.; Bahr, J.; Chisholm, B.J. Release characteristics of reattached barnacles to non-toxic silicone coatings. Biofouling 2008, 24, 313-319. [CrossRef] [PubMed]

22. Kim, S.-H.; Lee, S.; Ahn, D.; Park, J.Y. PDMS double casting method enabled by plasma treatment and alcohol passivation. Sens. Actuators B Chem. 2019, 293, 115-121. [CrossRef]

23. Leonardi, A.K.; Ober, C.K. Polymer-Based marine antifouling and fouling release surfaces: Strategies for synthesis and modification. Annu. Rev. Chem. Biomol. Eng. 2019, 10, 241-264. [CrossRef] [PubMed]

24. Shao, Y.; Du, W.; Fan, Y.; Zhao, J.; Zhang, Z.; Ren, L. Near-infrared light accurately controllable superhydrophobic surface from water sticking to repelling. Chem. Eng. J. 2022, 427, 131718. [CrossRef]

25. Esfandeh, M.; Mirabedini, S.M.; Pazokifard, S.; Tari, M. Study of silicone coating adhesion to an epoxy undercoat using silane compounds. Colloids Surf. A 2007, 302, 11-16. [CrossRef]

26. Liu, C.; Ma, C.; Xie, Q.; Zhang, G. Self-repairing silicone coatings for marine anti-biofouling. J. Mater. Chem. A 2017, 5, 15855-15861. [CrossRef]

27. Beaugendre, A.; Degoutin, S.; Bellayer, S.; Pierlot, C.; Duquesne, S.; Casetta, M.; Jimenez, M. Self-Stratification of ternary systems including a flame retardant liquid additive. Coatings 2018, 8, 448. [CrossRef]

28. Baghdachi, J.; Perez, H.; Talapatcharoenkit, P.; Wang, B. Design and development of self-stratifying systems as sustainable coatings. Prog. Org. Coat. 2015, 78, 464-473. [CrossRef]

29. Beaugendre, A.; Degoutin, S.; Bellayer, S.; Pierlot, C.; Duquesne, S.; Casetta, M.; Jimenez, M. Self-stratifying coatings: A review. Prog. Org. Coat. 2017, 110, 210-241. [CrossRef]

30. Beaugendre, A.; Saidi, S.; Degoutin, S.; Bellayer, S.; Pierlot, C.; Duquesne, S.; Casetta, M.; Jimenez, M. One pot flame retardant and weathering resistant coatings for plastics: A novel approach. RSC Adv. 2017, 7, 40682-40694. [CrossRef]

31. Joo, M.; Cakmak, M.; Soucek, M.D. Corrosion resistance of self-stratifying coatings using fluorovinyl ether/BPA epoxide. Prog. Org. Coat. 2019, 133, 145-153. [CrossRef]

32. Langer, E.; Kuczyńska, H.; Kamińska-Tarnawska, E.; Łukaszczyk, J. Self-stratifying coatings containing barrier and active anticorrosive pigments. Prog. Org. Coat. 2011, 71, 162-166. [CrossRef]

33. Beaugendre, A.; Degoutin, S.; Bellayer, S.; Pierlot, C.; Duquesne, S.; Casetta, M.; Jimenez, M. Self-stratifying epoxy/silicone coatings. Prog. Org. Coat. 2017, 103, 101-110. [CrossRef]

34. Zahedi, S.; Zaarei, D.; Ghaffarian, S.R. Self-stratifying coatings: A review. J. Coat. Technol. Res. 2018, 15, 1-12. [CrossRef]

35. Hu, P.; Xie, Q.; Ma, C.; Zhang, G. Fouling resistant silicone coating with self-healing induced by metal coordination. Chem. Eng. J. 2021, 406, 126870. [CrossRef]

36. Gurunathan, T.; Chung, J. Physicochemical Properties of Amino-SilaneTerminated Vegetable Oil-Based Waterborne Polyurethane Nanocomposites. ACS Sustain. Chem. Eng. 2016, 4, 4645-4653. [CrossRef]

37. Wang, X.; Pang, B.; Zhu, Q.; Yu, J.; Dong, H.; Dong, L. Electrical properties of acrylic resin composite thin films with graphene/silver nanowires. J. Appl. Polym. Sci. 2015, 132, 42387. [CrossRef]

38. Salta, M.; Wharton, J.A.; Blache, Y.; Stokes, K.R.; Briand, J.F. Marine biofilms on artificial surfaces: Structure and dynamics. Environ. Microbiol. 2013, 15, 2879-2893. [CrossRef] 